\title{
Controllability of an aircraft with active high-lift system using a segmentwise controllable flap system
}

\author{
Jobst Henning Diekmann ${ }^{1} \cdot$ Maximilian Pichler ${ }^{1} \cdot$ Meiko Steen $^{2} \cdot$ Peter Hecker $^{2}$
}

Received: 23 May 2017/Revised: 30 January 2018 / Accepted: 12 April 2018

(C) Deutsches Zentrum für Luft- und Raumfahrt e.V. 2018

\begin{abstract}
Active high-lift aircraft needs exceptional aerodynamic control performance to operate at low airspeed. In this study, a new concept for the improvement of controllability is investigated, incorporating the special capabilities of a blown Coandă flap system. The blowing system along the flaps is divided into 12 independently controllable segments. This provides the opportunity to influence the lift distribution along the wingspan by individual blowing performance settings for each segment without changing the flap deflection. This offers the chance to control the airplane in the final approach phase with fully deflected flaps using only the blowing system and to dedicate specific control tasks to particular segments. A model for the blowing system influence on the local wing aerodynamics is implemented in an existing nonlinear full aircraft flight mechanics model. The system capabilities in terms of roll control and the climb performance are investigated by criteria' evaluation and dynamic simulation assessment. The ability to fly turn/altitude change maneuvers by utilizing the active high-lift system is proven and a corresponding control concept is presented. It also includes the compensation of different blowing failure cases, which leads to acceptable but still improvable aircraft reactions.
\end{abstract}

Keywords Active high-lift · Boundary layer control flaps · Multifunctional flaps · Flow control · Flight mechanics · Feedback control system

\section{List of symbols}

$C_{L}, \tilde{C}_{L} \quad$ Lift coefficient, with segment failure

$C_{\mu}, \bar{C}_{\mu} \quad$ Jet momentum coefficient, global

$d C \quad$ Local coefficient

E Failure factor

$g \quad$ Gravitational acceleration, $\mathrm{m} / \mathrm{s}^{2}$

$H, \dot{H} \quad$ Altitude, $\mathrm{m}$, vertical speed, $\mathrm{m} / \mathrm{s}$

$K \quad$ Gain

Jobst Henning Diekmann

jobst.diekmann@dlr.de

Maximilian Pichler

maximilian.pichler@dlr.de

Meiko Steen

m.steen@tu-bs.de

Peter Hecker

p.hecker@tu-bs.de

1 Institute of Flight Systems, DLR, Lilienthalplatz 7, 38108 Brunswick, Germany

2 Institute of Flight Guidance, Technical University of Braunschweig, Herman-Blenk-Str. 27, 38108 Brunswick, Germany

$\begin{array}{ll}k & \text { Gradient } \\ m, \dot{m} & \text { Mass, kg, massflow, } \mathrm{kg} / \mathrm{s} \\ \dot{p} & \text { Roll acceleration, }{ }^{2} \mathrm{~s}^{2} \\ p, q, r & \text { Rotational rates, } \mathrm{s}^{\mathrm{s}} \\ q_{\infty} & \text { Free stream dynamic pressure, } \mathrm{N} / \mathrm{m}^{2} \\ S & \text { Reference wing area, } \mathrm{m}^{2} \\ s & \text { Half wing span, } \mathrm{m} \\ t & \text { Time, s } \\ t_{\Delta \Phi 30} & \text { Time to reach bank angle of } \Phi=30^{\circ}, \mathrm{s} \\ T & \text { Throttle setting, } \% \\ T_{\mathrm{R}} & \text { Roll time constant, } \mathrm{s} \\ V & \text { Velocity, m/s } \\ v_{\mathrm{jet}} & \text { Velocity of blowing airflow, } \mathrm{m} / \mathrm{s} \\ Y & \text { Normalized half wingspan } \\ \alpha & \text { Angle of attack, }{ }^{\circ} \\ \beta & \text { Sideslip angle, }{ }^{\circ} \\ \zeta & \text { Rudder deflection, }{ }^{\circ} \\ \delta_{\mathrm{fl}} & \text { Flap deflection, }\end{array}$


$\Phi \quad$ Bank angle, ${ }^{\circ}$

$\chi, \dot{\chi} \quad$ Flight-path azimuth, ${ }^{\circ}$, -rate $\%$

$\omega_{0} \quad$ Eigen frequency, $\mathrm{rad} / \mathrm{s}$

\section{Subscript}

AC Aircraft

c Command

FF Feed-forward

fli Flap segment $i$

in Input values

$j \quad$ Normalized wing span coordinate

jet Blowing system

L Lift

1 Rolling moment

lift HLS lift control input

max Maximum

n Aerodynamic data preset

roll HLS roll control input

WF Wing-fuselage

$\begin{array}{ll}\text { Abbreviations } \\ \text { BLC } & \text { Boundary layer control } \\ \text { CFD } & \text { Computational fluid dynamics } \\ \text { DoF } & \text { Degrees of freedom } \\ \text { HLS } & \text { High-lift system } \\ \text { MAC } & \text { Mean aerodynamic chord } \\ \text { MIL-HDBK } & \text { Military handbook } \\ \text { MTOW } & \text { Maximum take-off weight } \\ \text { NAL } & \text { National Aerospace Laboratory of Japan } \\ \text { NASA } & \text { National Aeronautics and Space } \\ & \text { Administration } \\ \text { PID } & \text { Proportional-integral-derivative (controller) } \\ \text { PrADO } & \text { Preliminary aircraft design and optimization } \\ & \text { (tool) } \\ \text { SC } & \text { Super circulation } \\ \text { SFB } & \text { Sonderforschungsbereich (Collaborative } \\ & \text { research center) } \\ \text { SHP } & \text { Shaft horsepower } \\ \text { STOL } & \text { Short take-off and landing }\end{array}$

\section{Introduction}

In the active high-lift research, various technologies have been tested to achieve short take-off and landing (STOL) capabilities for aircraft $[1,2]$. For the capability to fly at low airspeed, most of these technologies amplify the common passive flap system's lift performance by active flow control or use thrust vectoring or propeller slipstream deflection [3]. The goal of the Sonderforschungsbereich 880 (collaborative research center, SFB 880) is to advance the knowledge about efficient active high-lift technologies for a commercial transport type aircraft. It is envisioned

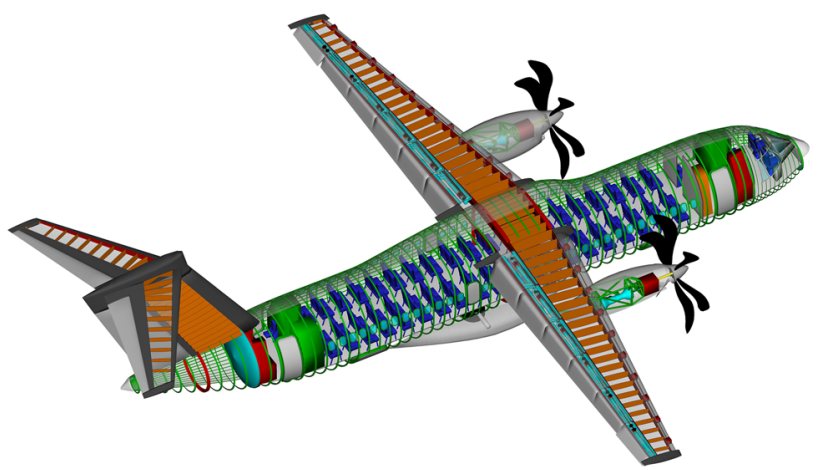

Fig. 1 SFB 880 aircraft design in landing configuration

that such aircraft can operate from small existing airfields in the close vicinity of large cities to spread the more and more saturated air traffic in the urban areas. To this end, a preliminary aircraft design has been created with the aircraft design tool PrADO [4], depicted in Fig. 1. The basic data of the aircraft design are provided in Table 1.

The concept comprises an active high-lift system (HLS), which uses a single-hinged plain flap with tangential blowing for boundary layer control. The flap utilizes the Coandă effect [5] by a specifically shaped surface at the knee of the flap. Therefore, a thin jet of air is blown with higher velocity than the surrounding airflow over this curved part of the wing profile. Momentum losses in the boundary layer of the airfoil depending on the flap deployment angle usually lead to flow separation in this area, which shall be compensated by this thin jet. By refreshing the boundary layer with the jet and developing lower pressure at the curved airfoil surface, both the thin jet and the surrounding airflow can be deflected. This way, the airflow can follow a high camber airfoil, a blunt wing trailing edge, or a strongly deflected flap. This increases the circulation around the airfoil and thus the lift generated by this airfoil. It appears to be an efficient approach with a

Table 1 SFB 880 aircraft basic data

\begin{tabular}{lll}
\hline & Metric & Imperial \\
\hline Wing area & $95 \mathrm{~m}^{2}$ & $1022.6 \mathrm{ft}^{2}$ \\
Horizontal tail area & $27 \mathrm{~m}^{2}$ & $290.63 \mathrm{ft}^{2}$ \\
Vertical tail area & $27 \mathrm{~m}^{2}$ & $290.63 \mathrm{ft}^{2}$ \\
Wing span & $28.775 \mathrm{~m}$ & $94.406 \mathrm{ft}$ \\
MAC & $3.428 \mathrm{~m}$ & $11.245 \mathrm{ft}$ \\
Aspect ratio & 9 & \\
Incidence angle & $10^{\circ}$ & \\
Dihedral angle & $-2^{\circ}$ & $91322 \mathrm{lbs}$ \\
MTOW & $41.423 \mathrm{t}$ & $2 \times 11381.4 \mathrm{SHP}$ \\
Engines & $2 \times 8482.9 \mathrm{~kW}$ & $2 \times 19797.4 \mathrm{lbf}$ \\
Static Thrust & $2 \times 88.063 \mathrm{kN}$ & \\
\hline
\end{tabular}


promising efficiency ratio between the necessary additional energy investment and the achievable high-lift gains, as only thin jets and small air mass flows (compared to jet flaps or upper surface blowing) are necessary to keep the flow attached to the wing profile even with large flap deflections. The blowing performance can be expressed by the jet momentum coefficient $C_{\mu}$ [2] calculated by the following:

$C_{\mu}=\frac{\dot{m}_{\mathrm{jet}} \cdot v_{\mathrm{jet}}}{q_{\infty} \cdot S}$.

It is the ratio of the jet air mass flow $\dot{m}_{\text {jet }}$ and its fluid velocity $v_{\text {jet }}$ to the dynamic pressure $q_{\infty}$ of the freestream and a reference area (in this case, the wing area $S$ ). The behavior of the lift coefficient with increasing jet momentum and the corresponding states of flow control for a wing profile with a strong flap deflection are qualitatively depicted in Fig. 2.

With increasing blowing performance, a separated flow (Fig. 2a) starts to partially attach to a strongly deflected flap (Fig. 2b) until the blowing is sufficient to fully attach the flow (Fig. 2c). This region is called the boundary layer control (BLC) range in the following. A further increase of the blowing leads to an additional circulation increase called super circulation (SC, Fig. 2d). Figure 2 indicates

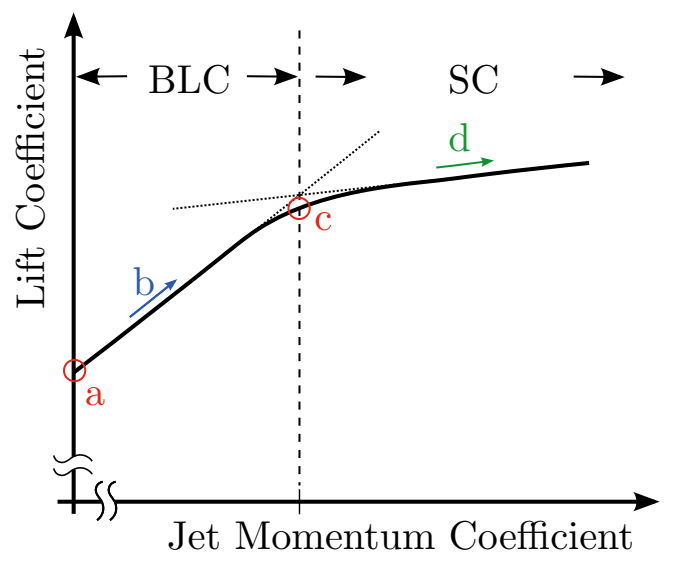

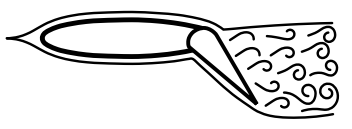

(a) Separated flow

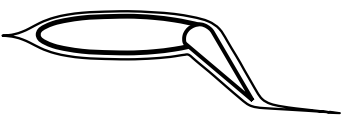

(c) Fully attached flow

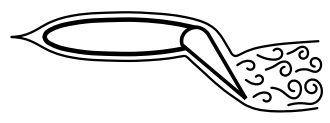

(b) Semi-attached flow

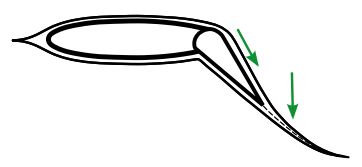

(d) Supercirculation
Fig. 2 Flow transition for blown flaps that the lift coefficient-to-blowing ratio and thus the efficiency are higher in the BLC range.

For the presented configuration, the beneficial effects of the blown flap system on lift will be supported by the propeller slipstream of the turbo-propeller engines. Similar configurations have been investigated by NASA [6-8] and NAL [9] in the 60s. These aircraft showed very good lowspeed performance. However, weight penalties and handling problems in the lateral-directional plane occurred. The high-lift systems were driven by an additional heavy jet engine for bleed air generation, without precise flow control at the slots and nozzles. However, the suitability for commercial transport could not be proven by corresponding studies [10, 11]. The studies stated that a reduction of the desired runway length by installing active high-lift systems certainly increases the direct operating cost, due to increased structural weight, power consumption, and maintenance cost. Therefore, a commercial use was only expected for special tasks operations. In addition, the technology is sensitive to engine failures, as well as problems to equally balance and precisely control the air mass flow distribution along the wingspan can occur [12].

The technological capabilities evolved since that time, so that a reconsideration of such configurations appears reasonable. Throughout the SFB 880 aircraft design stages, the source for pressurized air changed from a bleed air concept to a distributed micro-compressor approach. A distribution of the pressured air sources by means of microcompressors at the knee of the flap spread along the wingspan enables a direct access to precisely control the HLS wing segment wise. This allows for accurate flow control to efficiently achieve high-lift coefficient values, e.g., to keep the flow condition of Fig. 2c along the wingspan. Another opportunity occurs due to the spanwise segmentation of the HLS in terms of dedicated flight control tasks for particular segments. Recent research activities with unmanned aerial vehicles demonstrate the capability to use flow control systems for primary flight control [13]. It appears to be possible to implement similar capabilities for this transport type aircraft by individually controlling each single HLS segment. This offers the chance to control both, rolling and climb/descent motion, with the same system at the same time and without a change of the flap deflection angle.

For this purpose, a spanwise aerodynamic model has been developed to describe the lift distributions and rolling moments due to such individually controlled HLS segments. An existing Six-Degrees-of-Freedom (6-DoF) flight mechanics model has been extended with this submodel to assess the controllability of such systems. In a first step, the focus lies on the blown flap system only, so that the influences of the propeller slipstream are neglected. Hence, it is assumed to have jet engines installed at the aircraft for 
propulsion without interfering with the airflow around the wing or the HLS. Additional beneficial effects of boundary layer suction by properly placed compressor intakes [14] are neglected as well in this first modeling approach.

\section{Modeling approach}

The flight dynamics of the aircraft are simulated by a 6-DoF flight mechanics model based on nonlinear highfidelity 3D CFD data sets created by partner projects of the SFB 880 [15]. The modeling approach follows a classical point mass approach with the acting forces and moments calculated by dimensionless coefficients. The specific characteristics are considered by custom increment models describing the linear and nonlinear effects of a blown flaps system on aerodynamics. The models for lift and pitching moment separate the aerodynamics of the horizontal tailplane from the wing/fuselage (WF), recombined by a downwash model to describe the specific characteristics of the flaps system. A detailed description of the full aircraft model, its development stages, and the current model structure can be found in [16-18]. For the following investigations, the aircraft is assumed to be configured for the final approach phase with full flap deflection.

With the fully deflected blown single-hinged flap system $\left(\delta_{\mathrm{fl}}=65^{\circ}\right)$, the aircraft achieves remarkable lift performance, as can be seen in Fig. 3. It shows the three lift coefficient curves for different global jet momentum coefficients from the semi-attached flow condition for $C_{\mu, 2}=0.022$ (see Fig. 2b) to the circulation increase condition for $C_{\mu, 4}=0.045$ (see Fig. 2d). The lift coefficient for a completely separated flow at $C_{\mu 1}=0$ is not depicted. The fully attached flow condition as depicted in Fig. 2c, is

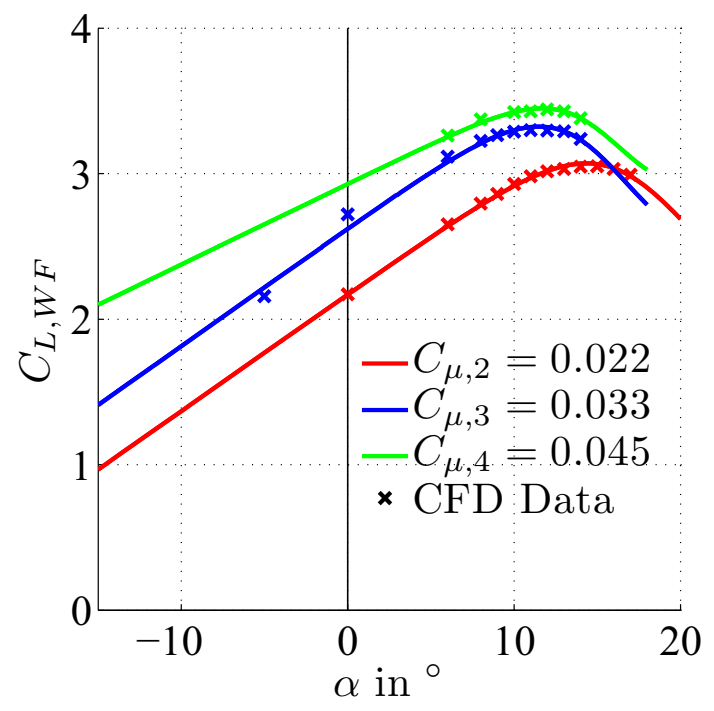

Fig. 3 Lift versus angle of attack for the wing/fuselage achieved at $C_{\mu, 3}=0.033$. This shall be the reference setting for the following studies, since it is considered to be the optimal operating point of the system.

The CFD data indicate a stall behavior with a typical trailing edge flow separation moving forward to the leading edge and spreading to wider wing areas with increasing angle of attack. The underlying model, therefore, assumes further lift loss in the post stall range. However, it is not intended to operate the aircraft in this region. For angles of attack below stall, linear aerodynamics are assumed, approximated to the available CFD data points. Taking this as the reference condition of the system, the spanwise aerodynamic model can now be set up as another increment to the full aircraft model.

\subsection{Spanwise active high-lift model}

To assess the controllability of the aircraft using only the active high-lift system without any flap deflection variation, a model for the blowing influence on the local segmented aerodynamics of the wing is necessary. The model approach used in this paper was developed in a previous investigation [19]. To that end, the wing flaps are divided into the segmentation of Fig. 4.

The main focus in the development of the model is on low computational effort for the capability to perform simulations in real-time. Therefore, simple linear interpolation methods based on high-fidelity 3D CFD results have been chosen over computationally intensive iterative methods. Common handbook methods are neglected as well, since they are not capable to describe the complex aerodynamics of such a flap system with the necessary precision.

The basis for modeling the increment in lift are the corresponding aerodynamic lift distributions for zero angle of attack from the CFD data sets for given global jet momentum coefficients. The here used data sets were given for the global coefficients $\bar{C}_{\mu, 2}=0.024, \bar{C}_{\mu, 3}=0.033$, and $C_{\mu, 4}=0.045$, slightly differing from the original full aircraft model values. Therefore, the original full aircraft model is kept at $C_{\mu, 3}=0.033$ as initial point for the new spanwise lift model. In addition, a zero blowing lift distribution was used. The global jet momentum describes the average momentum of the full wing with the full wing area $S$ as its reference plane. The local jet momentum coefficient can vary significantly form the global value due to different reference areas and compressor settings of each wing segment. It has to be noted that, in general, a global jet momentum coefficient value can be achieved by various individual local compressor settings and local jet momentum coefficients along the wingspan. In this case, the here used global jet momentum coefficients are representative 
Fig. 4 Segmentation of the high-lift system

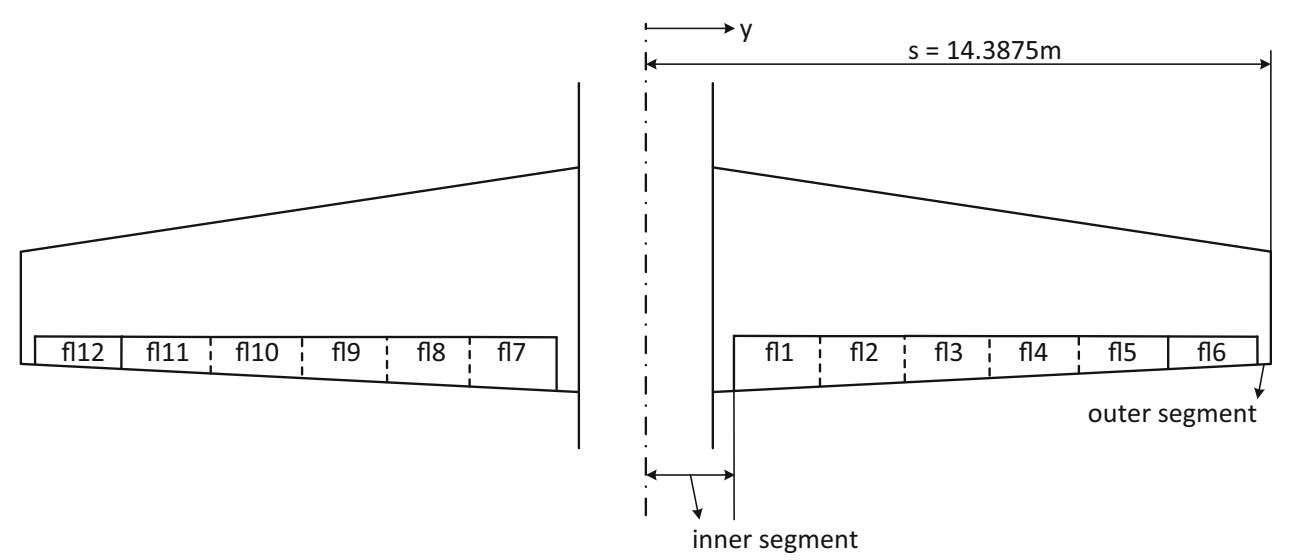

for specific local jet momentum setups. The global jet momentum coefficient is used as the control input for the overall performance of the blowing system.

The wingspan is divided into the discretization points $j$. At each discretization point $j$, the local lift $d C_{\mathrm{L}, j}$ for a jet momentum command $\bar{C}_{\mu, c}$ is determined by interpolation between the different aerodynamic data presets for the $n=$ 1,2,3,4 global jet momentum coefficients $d C_{\mathrm{L}, j}\left(\bar{C}_{\mu, n}\right)$. Therefore, the gradients $k$ between each data set have to be calculated:

$$
\begin{aligned}
k_{12, j} & =\frac{d C_{L, j}\left(\bar{C}_{\mu, 2}\right)-d C_{L, j}\left(\bar{C}_{\mu, 1}\right)}{\bar{C}_{\mu, 2}-\bar{C}_{\mu, 1}} \\
& =\frac{d C_{L, j}\left(\bar{C}_{\mu, 2}\right)-d C_{L, j}\left(\bar{C}_{\mu, 1}\right)}{\bar{C}_{\mu, 2}} \\
k_{23, j} & =\frac{d C_{\mathrm{L}, j}\left(\bar{C}_{\mu, 3}\right)-d C_{\mathrm{L}, j}\left(\bar{C}_{\mu, 2}\right)}{\bar{C}_{\mu, 3}-\bar{C}_{\mu, 2}} \\
k_{34, j} & =\frac{d C_{L, j}\left(\bar{C}_{\mu, 4}\right)-d C_{\mathrm{L}, j}\left(\bar{C}_{\mu, 3}\right)}{\bar{C}_{\mu, 4}-\bar{C}_{\mu, 3}} .
\end{aligned}
$$

These gradients are illustrated in Fig. 5a.

The lift increment of each discretization point $j$ can be calculated by the following:

$$
\begin{aligned}
d C_{L, j}\left(\bar{C}_{\mu, c}\right)= & d C_{L, j}\left(\bar{C}_{\mu 1}\right)+k_{12, j} \cdot\left\{\bar{C}_{\mu, c}-\bar{C} \mu, 1\right\} \\
& +k_{23, j} \cdot\left\{\bar{C}_{\mu, c}-\bar{C}_{\mu, 2}\right\} \\
& +k_{34, j} \cdot\left\{\bar{C}_{\mu, c}-\bar{C}_{\mu, 3}\right\}
\end{aligned}
$$

with the case consideration for the jet momentum coefficient command

$$
\left\{\bar{C}_{\mu, c}-\bar{C}_{\mu, n}\right\}=\left\{\begin{array}{lr}
0 & \text { for } \bar{C}_{\mu, c}<\bar{C}_{\mu, n} \\
\left(\bar{C}_{\mu, c}-\bar{C}_{\mu, n}\right) & \text { for } \bar{C}_{\mu, c}>\bar{C}_{\mu, n} .
\end{array}\right.
$$

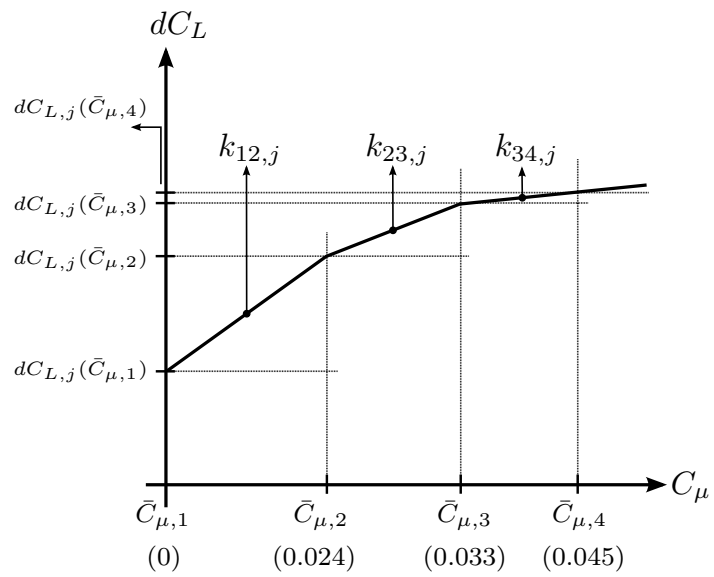

(a) Local lift gradients for the global jet momentum coefficient

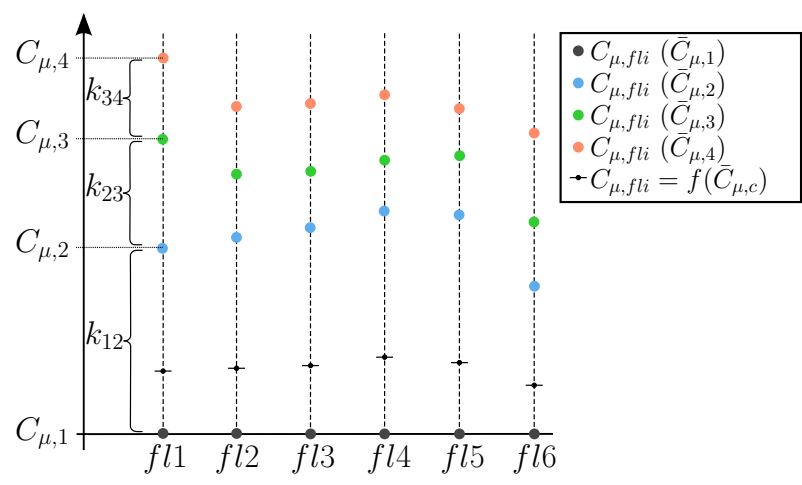

(b) Mapping factor from the global jet momentum to the local jet momentum

Fig. 5 Lift gradients and mapping factors [19]

It is now possible to change the overall lift distribution as a function of the global jet momentum coefficient $\bar{C}_{\mu}$. However, for further investigation, it is necessary to describe the compressor influence at each segment on the local and global lift. The model is extended for considering 
each flap segment fli, by varying the jet momentum of a specific flap segment $C_{\mu, f l i}$. Thus, it is possible to change the lift distribution over the corresponding flap segment. Therefore, the global jet momentum coefficient $\bar{C}_{\mu}$ is replaced by $C_{\mu, \mathrm{fli}}$.

As mentioned before, choosing a global jet momentum coefficient results in a certain distribution of local compressor performance settings and thus local jet momentum coefficients. Due to CFD data, the local compressor setting for given values of the global jet momentum coefficient is known. The mapping shown in Fig. 5b generates local compressor setting commands for a global jet momentum coefficient command.

The local contribution at each discretization point $j$ to the rolling moment can be calculated by considering the corresponding dimensionless lever arm of the local lift $Y_{j}$ and the local lift coefficient:

$d C_{\mathrm{l}, j}=d C_{\mathrm{L}, j} \cdot Y_{j}$.

To describe induced aerodynamic effects, it is necessary to consider the interaction between each flap segment by varying the compressor inputs. This includes a failure model to describe the influence of a compressor failure on the lift distribution. This influence along the halfspan is described by a factor model. The lift at each discretization point is reduced by the failure factor: $E_{\mathrm{L}, j}$

$d \tilde{C}_{\mathrm{L}, j}=d C_{\mathrm{L}, j} \cdot\left(1-E_{\mathrm{L}, j}\right)$.

The failure factor $E_{\mathrm{L}}$ defines the percentile lift loss due to blowing failure at each discretization point based on a segment 4 failure:

$E_{\mathrm{L}, j, f l 4}=1-\frac{d C_{\mathrm{L}, j}\left(\bar{C}_{\mu, 5}\right)-d C_{\mathrm{L}, j}\left(\bar{C}_{\mu, 1}\right)}{d C_{\mathrm{L}, j}\left(\bar{C}_{\mu, 3}\right)-d C_{\mathrm{L}, j}\left(\bar{C}_{\mu, 1}\right)}$.

The segment 4 failure case was determined by CFD data and is the basis for modeling the remaining segment failure cases. Detailed information about the model development can be found in the previous studies [19]. Equation (9) is determined by the ratio between the lift distribution at the global jet momentum coefficient $\bar{C}_{\mu, 3}$ and the complete shutdown of the active high-lift system $\bar{C}_{\mu, 1}$ and the ratio between the segment 4 failure case $\bar{C}_{\mu, 5}$ and the complete shut down of the active high-lift system $\bar{C}_{\mu, 1}$. The final model can be described as follows:

$d \tilde{C}_{\mathrm{L}, j}=d C_{\mathrm{L}, j} \cdot\left(1-\sum_{i=1}^{6}\left(\kappa_{i} \cdot E_{\mathrm{L}, j, f l i}\right)\right)$.

To scale the level of the failure, the factor $\kappa$ is introduced. In this equation, the scaling factor is in the range of fully active $(\kappa=0)$ to a complete failure $(\kappa=1)$ and can be set individually for each segment. In the following model, the factor is used to manually control the compressor setting of each segment under the assumption of linear behavior. Due to the fact that Eq. (10) only allows a decrease in the compressor performance, the equation must be extended for an increase in jet momentum coefficient resulting in:

$d \tilde{C}_{\mathrm{L}, j}=d C_{\mathrm{L}, j} \cdot\left(1 \pm \sum_{i=1}^{6}\left(\kappa_{i} \cdot E_{\mathrm{L}, j f f l}\right)\right)$.

For a better understanding, the initially used range of the scaling factor $\kappa$ has been inverted for implementation in the flight dynamics model. In the following, the range will describe a complete failure by $\kappa=0$ up to increasing performance (increase in lift) described by $\kappa>1$. A more detailed description of the model structure and implementation can be found in the report [20].

\subsection{Spanwise lift model outputs}

The results of the developed model are presented in Fig. 6, where $Y$ is the dimensionless half wingspan coordinate. It can be seen in Fig. 6a that the model outputs (crossed

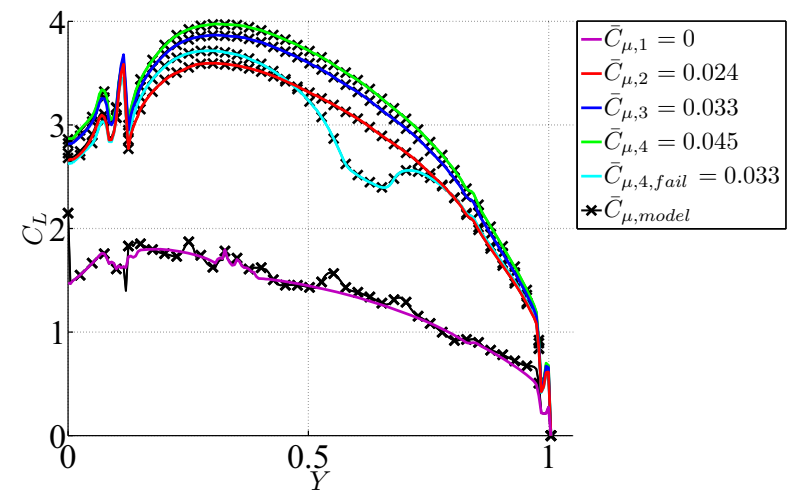

(a) Comparison between the aerodynamic CFD Dataset and the model output for presets and inoperative blowing system

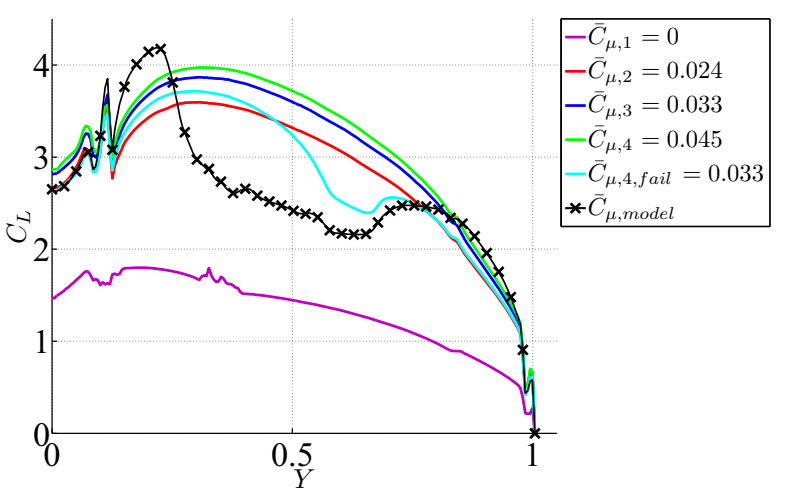

(b) Manually influenced lift distribution with different scaling factors $\left(\kappa_{1}=1.8, \kappa_{2}=0, \kappa_{3}=0.5, \kappa_{4}=0, \kappa_{5}=1.2, \kappa_{6}=2\right)$

Fig. 6 Lift distributions 
lines) fit the lift circulation data from 3D CFD (straight lines). It also shows the model output for a complete blowing system failure, which is based on the sum of all segment failure factors and shows an acceptable match with the corresponding CFD data. A modified lift distribution can be found in Fig. 6b. Different scaling factors for each segment are used to change the local lift. The combination of each change in the scaling factor results in the modified lift distribution. In a first step, the effect of draginduced yawing moments, which are expected to be less influencing, is neglected. Nonetheless, in a next model development step, this influence will be considered.

\section{Direct lift force and rolling motion due to blowing}

After the development of a model to describe the influence of compressor performance on local aerodynamics, the resulting flight dynamic reactions are now to be investigated. A mirror-symmetric actuation of the segmented compressors results in a direct lift force, which induces an increased or decreased climb rate. An asymmetric or pointsymmetric actuation causes primarily a rolling motion. The rolling and climbing reactions due to performance variations of the high-lift system (HLS) of each segment can be seen in Fig. 7.

The roll performance due to blowing is evaluated in terms of the Military Specifications MIL-HDBK-1797 [21]. The criteria applied in Fig. 7a requires to reach a $30^{\circ}$ bank angle within $2.5 \mathrm{~s}$ for a level 1 rating. It can be seen that the level 1 requirement is fulfilled by $47 \%$ increase in jet momentum coefficient at the most outboard segment (fl6). Using all six segments for rolling the minimum applied performance increase for each segment is $6 \%$ to reach the level 1 requirement. However, the more segments are used for a rolling motion, the less is the control performance increase per additional segment. Therefore, it is not reasonable to use all six segments for roll control. The outer three segments on both side of the wing are considered satisfactory for roll control.

Figure $7 \mathrm{~b}$ illustrates the level of controllability using preselected single segments in comparison with a conventional $40^{\circ}$ aileron deflection for roll control. This chart gathers multiple roll control criteria from the Military Specifications MIL-HDBK-1797 [21] and takes the actual roll time constant and the initial roll acceleration into consideration. It can be seen that the usage of local compressors for flight control predominantly results in better ratings for control, than the aileron. This allows the assumption that the active high-lift system can be used as an alternative option to the conventional control surfaces in the rolling motion. It is assumed that the roll damping

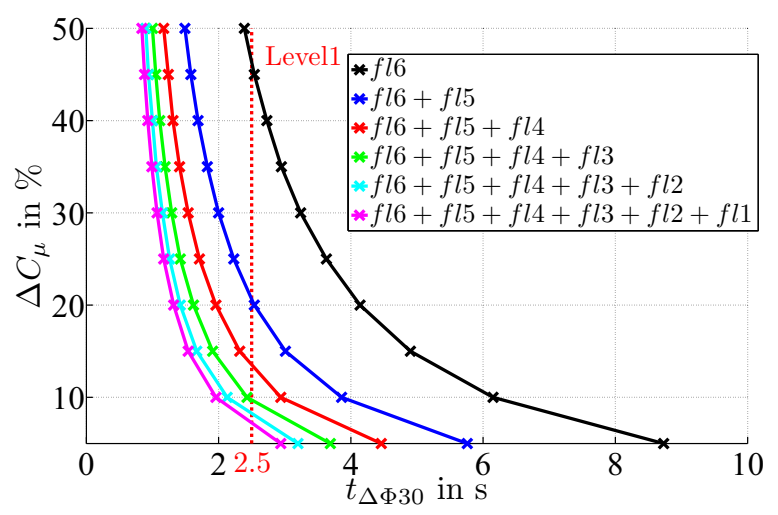

(a) Time to reach a bank angle of $30^{\circ}$ for different compressor actuation

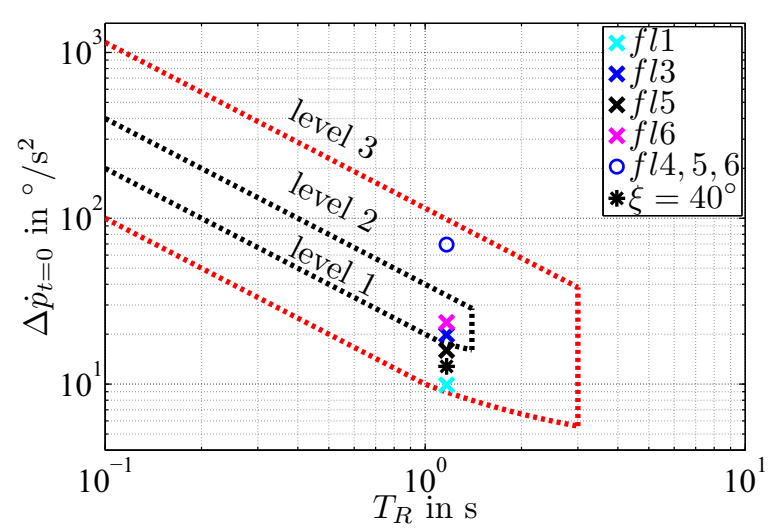

(b) Flying qualities in roll reaction as a function of roll acceleration and roll time constant

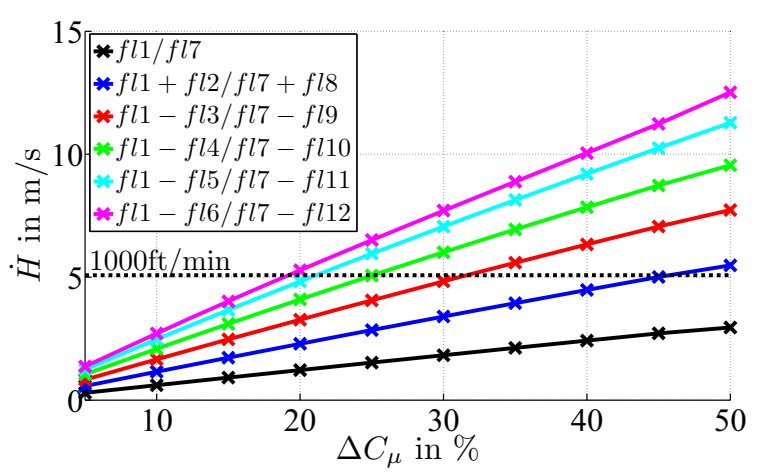

(c) Climb performance with different compressor segments

Fig. 7 Aircraft reaction on high-lift control inputs

of the aircraft, which mainly influences the roll time constant, is not influenced by the blowing system. The roll damping depends on the local lift curve slope of the wing profile along the wingspan, which is not significantly affected by the blowing system. Of course, this assumption only holds for local angles of attack in the linear aerodynamics range. The influence of highly 
dynamic rolling motions and resulting large local angles of attack is neglected.

The climb rate due to mirror-symmetrical increase in the segmented system's performance is shown in Fig. 7c. The climb rate increases with an increasing number of segments used. Using all 12 segments, the climb rate can reach a value up to $12 \mathrm{~m} / \mathrm{s}$ at an increase in each compressor performance of $50 \%$. For the following simulations, the inner three segments of each wing will be used for direct lift and, therefore, climb control.

\section{Controllability assessment}

The investigations in Sect. 3 demonstrated the ability to control the aircraft with the HLS-induced change in local aerodynamics at different maneuvers. In the following, the ability to fly combined maneuvers with the segmentation in roll and lift segments is assessed. The flight control strategy is presented before the corresponding simulation results are presented and discussed.

\subsection{Flight control concept}

To provide sufficient control for a maneuver flight, a flight control system for longitudinal and lateral control is developed, depicted in Fig. 8. The flight control system uses the six climb and six roll segments of the active HLS for control inputs. The conventional control surfaces of the aircraft are used only for damping the pitch, rolling, and yawing motion.

In the longitudinal plane, the velocity of the aircraft $V$ is kept constant by adapting the throttle setting $T_{\mathrm{c}}$. The climb is performed with a constant pitch attitude. Maintaining a constant pitch ensures that the climb is caused by a direct lift force due to increase in HLS performance, without a lift force due to thrust vector or attitude change. In this way, only the potential in climb performance due to blowing is considered. An additional part of the longitudinal control system is the capability to command a specific climb rate and acceleration. This is done by a flight-path generator. The structure of such a flight-path generator can be found in the literature [22]. The commands for the inner lift-generating system segments $\Delta C_{\mu, \text { lift }}$ are controlled by a PID controller for an accurate flight-path control. The gains used for longitudinal control are given in Table 2.

The structure of the longitudinal motion control system can be seen in Fig. 8a.

The structure of the lateral control system can be seen in Fig. 8b. The gains used in the lateral control system can be seen in Table 3.

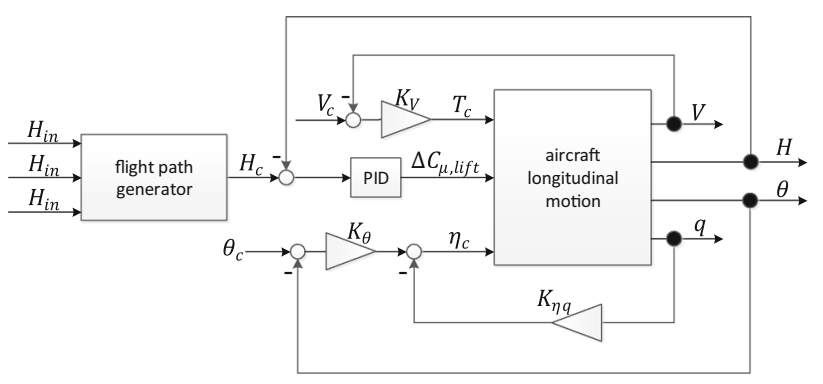

(a) Longitudinal control concept

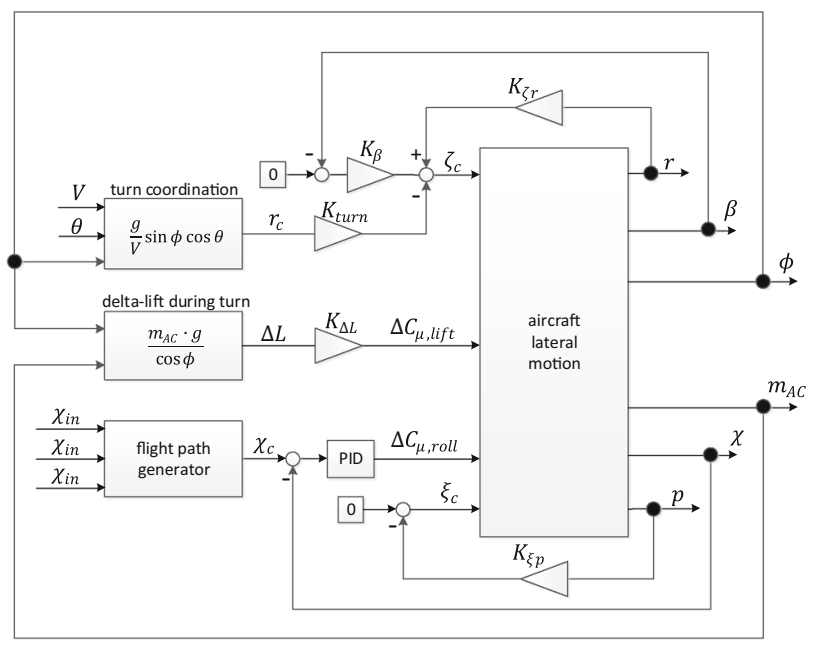

(b) Lateral control concept

Fig. 8 Block diagrams of the segmented high-lift control concepts

Table 2 Gain values used for longitudinal control

\begin{tabular}{lll}
\hline & Gain & Value \\
\hline Damping & $K_{\eta q, P}$ & 0.9 \\
Pitch & $K_{\theta, P}$ & 6 \\
& $K_{H C_{\mu, P}}$ & $0.7 \times 10^{-3}$ \\
Altitude & $K_{H C_{\mu}, I}$ & $0.1 \times 10^{-4}$ \\
& $K_{H C_{\mu}, D}$ & $3 \times 10^{-3}$ \\
Velocity & $K_{V, P}$ & 0.5 \\
\hline
\end{tabular}

The variable $\Delta C_{\mu, \text { roll }}$ represents the roll control input for the HLS. To ensure a proper control response, another PID controller is implemented. The rolling motion is slightly damped by a roll damping controller for the ailerons to prevent excessive roll accelerations. During a turn, the lift force counteracting the gravitational force needs to be increased to maintain altitude. This can be done by increasing the pitch attitude. The lift loss during a turn is compensated by the active HLS, as well $\left(\Delta C_{\mu, \text { lift }}\right)$, realized by a feed-forward calculation. Since a coordinated turn requires correctional rudder control inputs, a feed-forward calculation for a turn coordination is implemented in the 
Table 3 Gain values used for lateral control

\begin{tabular}{lll}
\hline & Gain & Value \\
\hline Roll damping & $K_{\xi p, P}$ & 0.5 \\
Turn control & $K_{\chi C_{\mu}, P}$ & 0.003 \\
& $K_{\chi C_{\mu}, I}$ & 0.001 \\
Yaw damping & $K_{\chi C_{\mu}, D}$ & 0.2 \\
Sideslip control & $K_{\zeta r, P}$ & 0.8 \\
Turn coordination & $K_{\beta, P}$ & 3.0 \\
Lift compensation curve & $K_{\mathrm{curve}, P}$ & 1.5 \\
\hline
\end{tabular}

control system. In addition, a sideslip controller is applied to maintain zero sideslip angle. Furthermore, it is possible to command a desired rate of turn and a desired initial roll acceleration. This system allows to investigate the resulting HLS performance and jet momentum coefficients for different turn conditions.

\subsection{Maneuver flight}

As a next step, simulations are conducted to investigate the aircraft response and the magnitude of the $C_{\mu}$ outputs to fly combined vertical and horizontal maneuvers. At the beginning of the simulation, a change in altitude and flightpath azimuth is commanded:

- $\Delta H=50 \mathrm{~m}$

- $\Delta \chi=50^{\circ}$.

There are two points of interest for this investigation. The first is the general ability to fly a maneuver with the developed high-lift control system and the second is the influence of the HLS characteristics on the maneuver.

The following results demonstrate the systems ability to perform the given task. The flown trajectories indicated by the altitude and flight-path azimuth and the corresponding jet momentum can be seen in Fig. 9. The commanded target values are indicated by red dashed lines in Fig. 9a, b. The dynamics of the compressors of the HLS are considered as a damped second-order oscillation. In the absence of corresponding information about the compressors dynamics, the initially used eigen frequency is assumed to be $\omega_{0}=19 \mathrm{rad} / \mathrm{s}$, which is a very quick reaction, so that the influence is marginal in the first place. However, it can be expected to have significantly lower response characteristics. Therefore, the influence of low compressor dynamics is part of the parameter studies in the following. The $C_{\mu}$ limit for each HLS segment is set to $C_{\mu, \max }=0.066$, which is considered to correspond to the maximum performance achievable by the compressors.

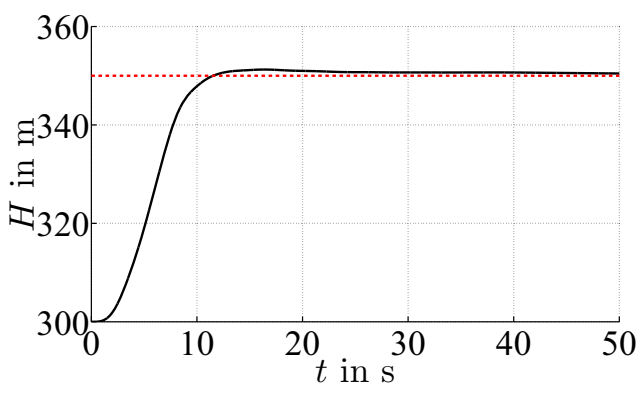

(a) Climb reaction

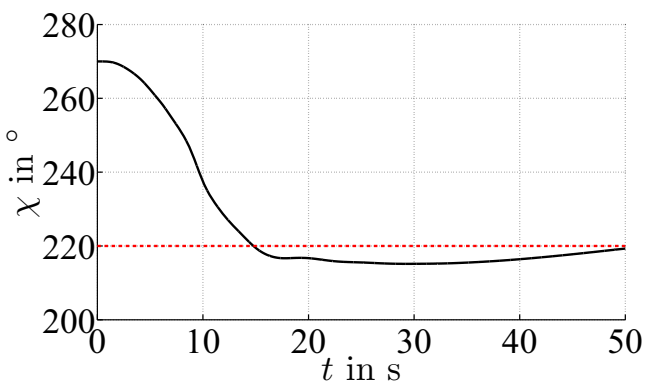

(b) Bank maneuver

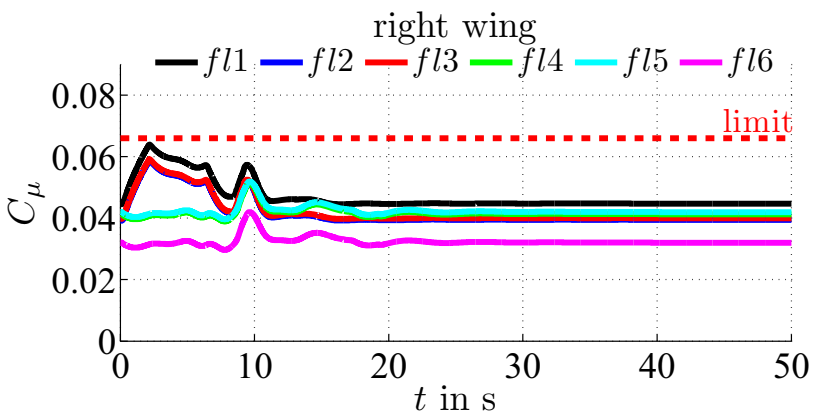

left wing

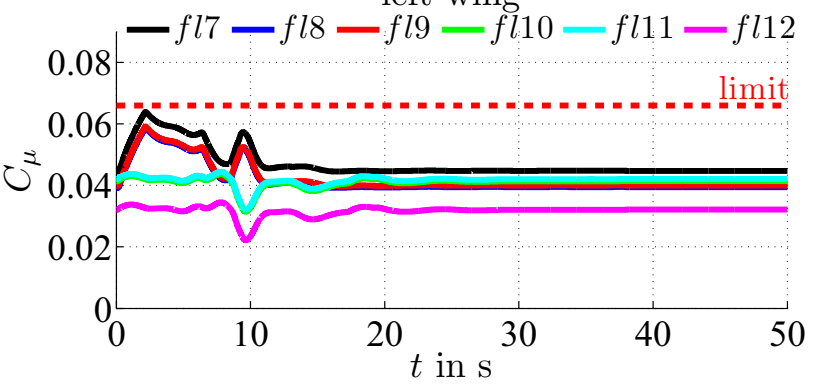

(c) Local jet momentum coefficients

Fig. 9 Aircraft reaction with a compressor eigen frequency of $\omega_{0}=19 \mathrm{rad} / \mathrm{s}, \dot{H}=8 \mathrm{~m} / \mathrm{s}$, and $\dot{\chi}=5 \% \mathrm{~s}$

As mentioned before, the climb rate and the turn rate can be manually selected using the flight-path generator. This maneuver represents the results for the maximum chosen steering inputs $(\dot{H}=8 \mathrm{~m} / \mathrm{s}$ and $\dot{\chi}=5 \%$ ). In general, the simulation with the developed flight control system shows good results. The HLS performance is no limiting factor for the desired maneuvers. The jet momentum coefficients for 
all 12 segments in Fig. 9c represent the control inputs used for this maneuver (note that some curves overlay each other). The use of the conventional control surfaces is not necessary to realize the intended change in azimuth and altitude (not depicted).

As mentioned before, a major influence to be investigated is the HLS's compressor dynamics. Therefore, the damping and eigen frequency of the compressors are varied. While the damping has no significant influence on the simulation results (not depicted), the most important characteristic is the eigen frequency. As can be seen in Fig. 10, the simulations are conducted with three different eigen frequencies $\left(\omega_{0}=1 \mathrm{rad} / \mathrm{s}, \omega_{0}=5 \mathrm{rad} / \mathrm{s}\right.$, and $\omega_{0}=10 \mathrm{rad} / \mathrm{s}$ ).

The results show that a maneuver flight with the lowest chosen eigen frequency is not possible, since the aircraft reactions become unstable. With the higher chosen $\omega_{0}=5 \mathrm{rad} / \mathrm{s}$ or $\omega_{0}=10 \mathrm{rad} / \mathrm{s}$ settings, the aircraft motion is stable. Between these higher frequencies, there is no significant difference in the flown trajectory. Since the compressor system is a part of the research of the SFB 880, the results of this study will be used to define a recommended level of dynamic reaction to achieve good aircraft control performance. The current status of the compressor development can be found in [23].

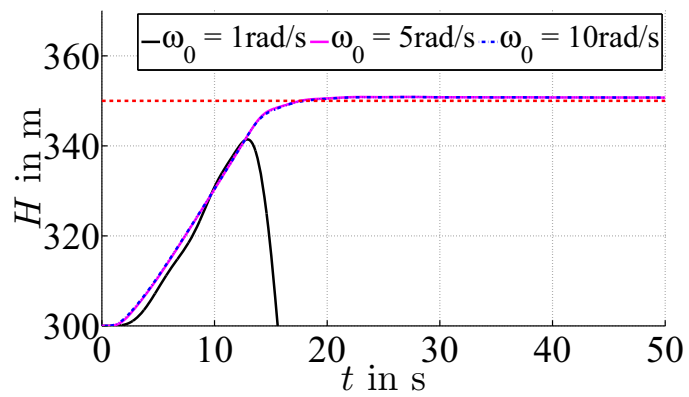

(a) Climb reaction

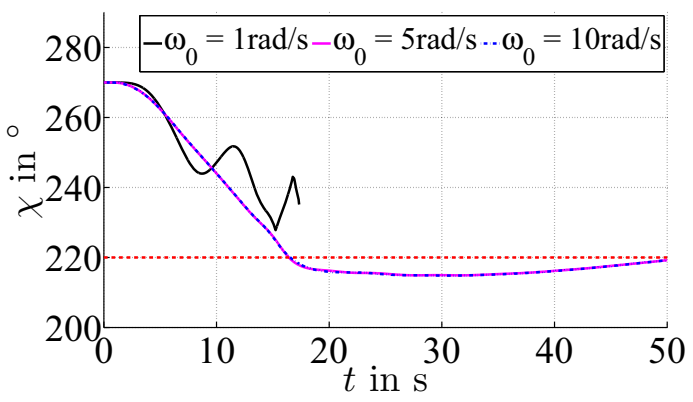

(b) Bank maneuver

Fig. 10 Aircraft reaction with different compressor eigen frequencies $\dot{H}=4 \mathrm{~m} / \mathrm{s}$ and $\dot{\chi}=3 \% \mathrm{~s}$

\section{Failure case compensation}

The previous investigations in Sect. 3 have shown the significant impact on local lift due to the variation of a single HLS segment. Therefore, it is easily understandable that a single compressor failure can cause a perceptible loss in lift and resulting rolling motion. Simulations have shown that the resulting rolling motion cannot be counteracted by the use of the currently installed ailerons. To counteract the rolling and lift loss, a failure control concept has been developed. The only option to compensate the reactions of a single segment failure is to adapt the performance of the remaining HLS segments. There are basically two possible methods.

The first method uses the corresponding opposite HLS segment. For example, if one HLS segment fails on the right wing, the corresponding segment on the left wing is turned off to avoid the resulting rolling motion. The loss of lift is compensated by adapting the output of the residual segments. The advantage is the straightforward avoidance of a rolling motion. However, by turning down an additional compressor, the lift will decrease further.

The second method considers only the six segments on the affected wing half. If one segment fails on one half of the wing, the rolling motion is compensated by adapting all five remaining segment outputs on this half. Using this method, there is a chance to simultaneously compensate both, the lift loss and the rolling motion, without switching off another compressor on the other wing half. However, due to various failure combinations and system limitations, a compensation of both is not always possible, since the wing half's lift and rolling moment depend on each other. Therefore, it is necessary prioritize the compensation targets. In this case, the prior target is the compensation of the rolling moment and a subsequent compensation of the remaining lift loss by the dedicated lift segments if necessary.

For further simulations, the second method is tested for its effectiveness. The model structure developed for the compensation of a single compressor failure is shown in Fig. 11.

The feed-forward calculation in the roll axis consists of an inverted aerodynamic model approach, using the derived aerodynamic model for the lift distribution to calculate a necessary segment $C_{\mu}$ to achieve a desired rolling moment. By doing this, it is possible to determine the necessary increase in $C_{\mu}$ of each segment on the affected wing for failure compensation. Due to the complexity of influences of the segments on each other in the HLS model, it is not tried to compensate the induced lift effects from other segments. Therefore, an additional roll 


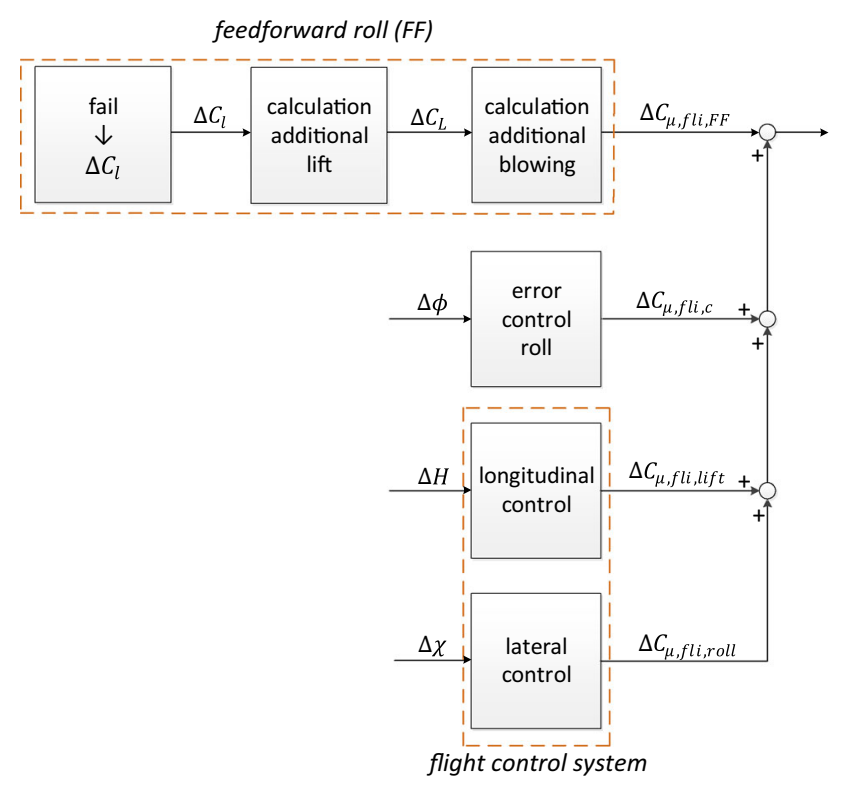

Fig. 11 Model structure for compensation of a single compressor failure

controller (error control roll) is implemented to maintain the desired bank angle. This controller enables to command any desired bank angle. Thus, it is possible to fly a bank maneuver even with an HLS failure. However, by commanding a desired bank angle, it cannot be ensured that the aircraft will stay on an assigned flight-path azimuth. Therefore, a lateral controller is necessary to maintain the intended course. The loss in altitude due to blowing failure is compensated by the already installed longitudinal controller. Both, the lateral and longitudinal controller, are already used for the dynamic simulations and are used here for compensation. A slight change in the gain values is necessary to adapt the controller response to the new model during compressor failure.

\subsection{Failure control concept assessment}

To investigate the effectiveness of the failure control system, dynamic simulations are conducted. The simulations start with an unaccelerated horizontal straight and level flight. At the beginning, a compressor is shut down and the failure control system is activated. The reactions of the aircraft and the failure control system are monitored. Table 4 gives the aircraft reactions in terms of maximum change in bank angle $\phi_{\max }$ and altitude $\Delta H_{\max }$ within the first five seconds of the simulations.

For a better understanding of the given values, the reactions at a global jet momentum coefficient of $\bar{C}_{\mu}=$ 0.024 are further detailed. Considering the failure case of the first segment, the maximum bank angle is $\Phi_{\max }=1.6^{\circ}$ and the maximum change in altitude will be $\Delta H=-1.8 \mathrm{~m}$.
The bank angle $\Phi_{\max }$ is the maximum value reached before the failure system corrects the bank angle back to horizontal flight. If the maximum change in altitude has a positive value, the failure control system compensates more lift than necessary, which results in a slight increase in altitude. This investigation is conducted with different segment failures and global jet momentum coefficients. The values in the tables show good results to counteract the flight mechanic reactions in case of a single compressor failure.

Another important finding are the single jet momentum coefficient values for each failure case. The resulting jet momentum coefficients for different failure cases and different global $\bar{C}_{\mu}$ values are presented in Fig. 12. To maintain controllability, it is important to preserve a certain margin in jet momentum. Once each segment reaches its maximum performance to counteract a single segment failure, there is no possibility to control the aircraft by further HLS inputs. As can be seen in the figures, the margin in each compressor decreases by increasing global jet momentum coefficients $\bar{C}_{\mu}$ as a result of the initially trimmed state of the HLS. Therefore, the ability to control the roll motion of the aircraft using the compressor outputs becomes more difficult with increasing global jet momentum coefficient.

The slight exceeding of the jet momentum above the defined maximum of $C_{\mu, \max }=0.066$ can be attributed to the overshoots of the dynamic model of the compressor.

\subsection{Maneuver flight with segment failure control}

In this section, a maneuver flight with a single segment failure is investigated. The previous analysis leads to the assumption that a maneuver flight using the active high-lift system becomes more difficult with increasing global jet momentum coefficient. This assumption is tested in the following. The maneuver to be flown is defined with a change in altitude and flight-path azimuth of:

- $\Delta H=50 \mathrm{~m}$

- $\Delta \chi=40^{\circ}$.

At the beginning of the simulation the flap segment three (fl3) will be shut down. The failure case system will counteract the aircraft's reaction as explained in the previous section. At the same time, the new commands in azimuth and altitude are given. All control inputs are performed by the segments of the active HLS only. This maneuver is tested with three different global jet momentum coefficients:

- $\bar{C}_{\mu}=0.024$

- $\bar{C}_{\mu}=0.033$

- $\bar{C}_{\mu}=0.045$. 
Table 4 Maximum bank angle and altitude loss for various jet momentum coefficients

\begin{tabular}{|c|c|c|c|c|c|c|}
\hline \multirow[t]{2}{*}{ Segment failure } & \multicolumn{2}{|c|}{$\bar{C}_{\mu}=0.024$} & \multicolumn{2}{|c|}{$\bar{C}_{\mu}=0.033$} & \multicolumn{2}{|c|}{$\bar{C}_{\mu}=0.045$} \\
\hline & $\Phi_{\max }\left(^{\circ}\right)$ & $\Delta H_{\max }(\mathrm{m})$ & $\Phi_{\max }\left({ }^{\circ}\right)$ & $\Delta H_{\max }(\mathrm{m})$ & $\Phi_{\max }\left({ }^{\circ}\right)$ & $\Delta H_{\max }(\mathrm{m})$ \\
\hline Seg. 1 & 1.6 & -1.8 & 1.2 & -0.8 & 1.4 & -0.5 \\
\hline Seg. 2 & 1.7 & -1.2 & 1.6 & -0.1 & 2.3 & -0.05 \\
\hline Seg. 3 & 1.8 & -1.0 & 1.8 & -0.3 & 2.6 & +0.5 \\
\hline Seg. 4 & 1.4 & -1.0 & 1.7 & -0.4 & 2.2 & +0.6 \\
\hline Seg. 5 & 1.4 & -1.0 & 1.6 & -0.5 & 2.2 & +0.7 \\
\hline Seg. 6 & 1.2 & -0.7 & 1.3 & -0.5 & 1.7 & +1.0 \\
\hline
\end{tabular}

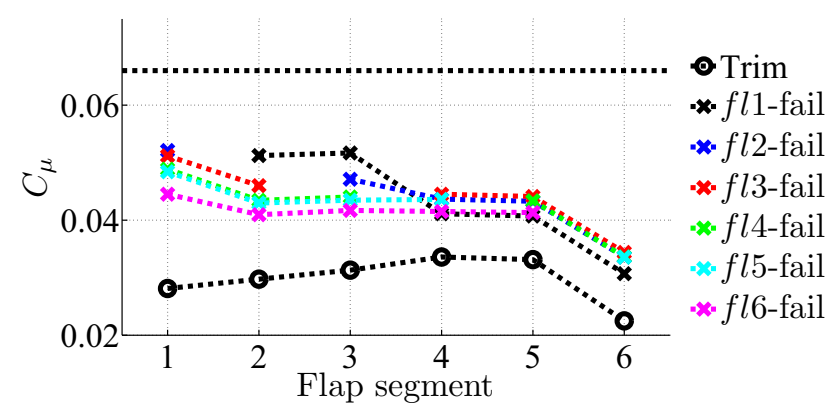

(a) $\bar{C}_{\mu}=0.024$

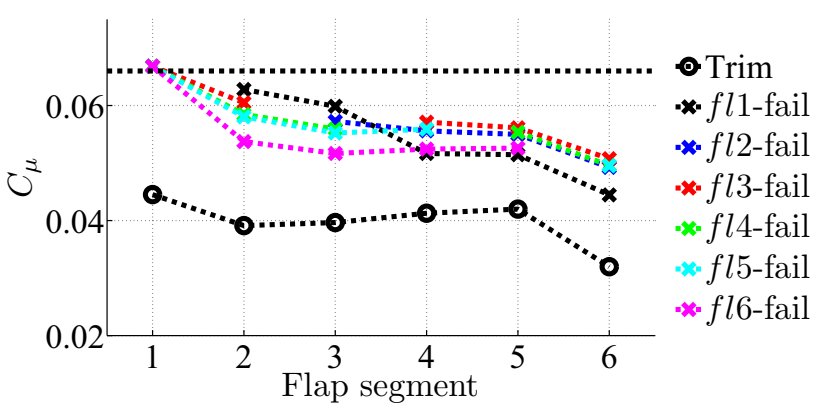

(b) $\bar{C}_{\mu}=0.033$

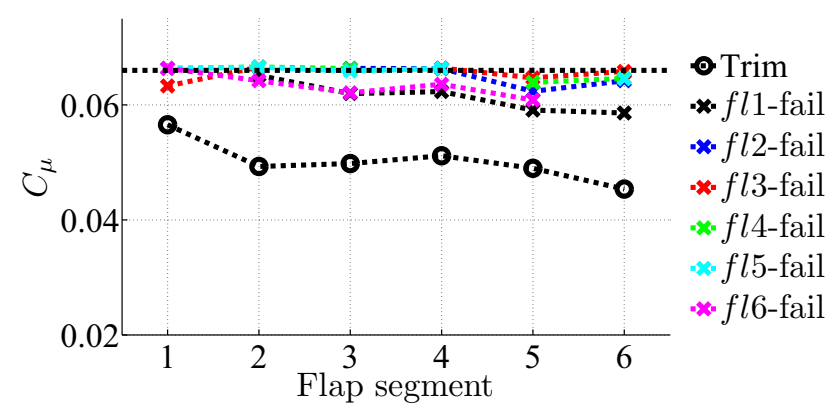

(c) $\bar{C}_{\mu}=0.045$

Fig. 12 Resulting compressor settings for different failure cases and different global jet momentum coefficients

The results of the simulations are shown in the Figs. 13 and 14. A simulation with the highest chosen jet momentum $\bar{C}_{\mu}=0.045$ quickly leads to saturated system states, and thus to insufficient controllability. Figure 13 shows the

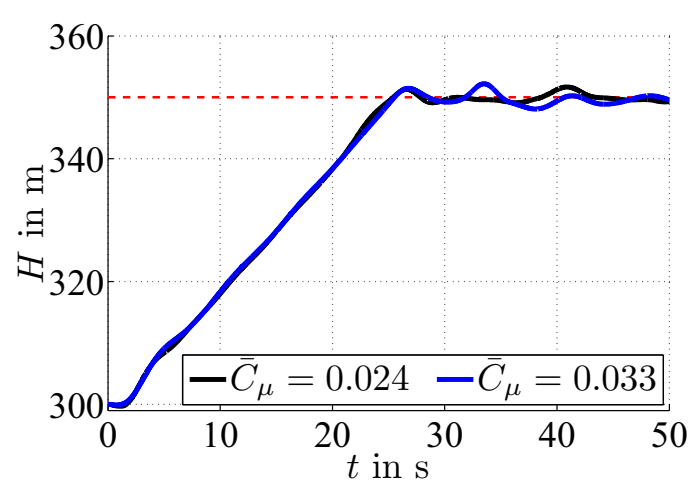

(a) Climb maneuver

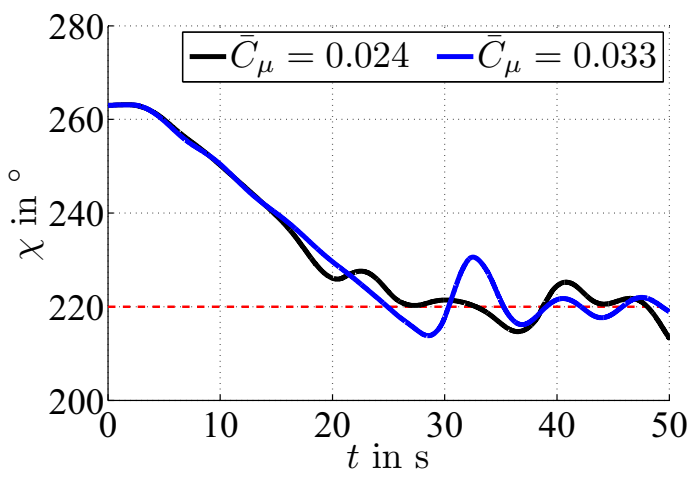

(b) Turn maneuver

Fig. 13 Aircraft reaction with a compressor eigen frequency of $\omega_{0}=19 \mathrm{rad} / \mathrm{s}, \dot{H}=2 \mathrm{~m} / \mathrm{s}$, and $\dot{\chi}=2 \% \mathrm{~s}$

vertical flight-path and the flight-path azimuth of the aircraft with the corresponding vertical speeds and turn rates. Basically, the desired altitude and heading are achieved, but the approach to the commanded value shows weakly damped or even unsteady behavior. In both cases, an oscillation of the flight-path can be seen. The reason for this unstable behavior can be explained by analyzing the $C_{\mu}$ time histories in Fig. 14, which show temporary saturation throughout the maneuver. In general, the chosen method for controlling the aircraft with use of the remaining segments of the affected wing has reached its limits for both maneuvers. Hence, the tendency to unstable behavior becomes stronger with increasing global jet 

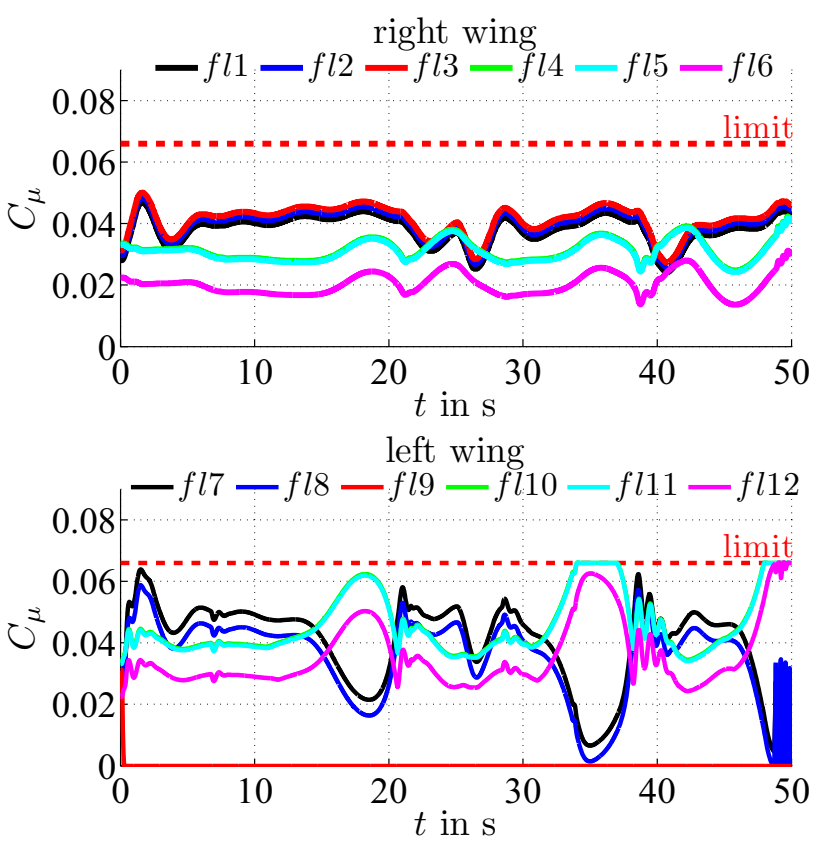

(a) $\bar{C}_{\mu}=0.024$

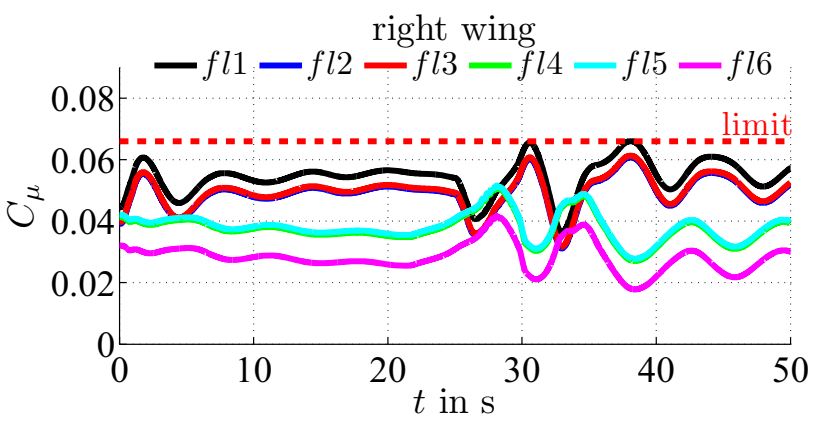

left wing

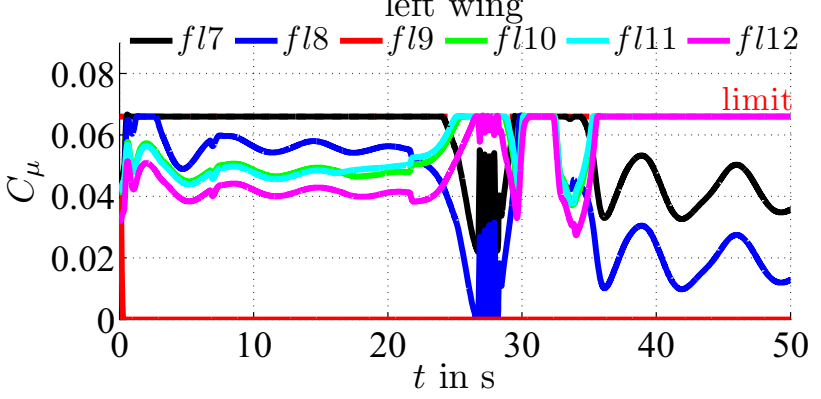

(b) $\bar{C}_{\mu}=0.033$

Fig. 14 Resulting high-lift system settings for different failure cases and global jet momentum coeffcients

momentum coefficient. A possible solution to prevent saturated HLS segment performance is to increase the support by the conventional aileron and to optimize the controller gains for damping and turn coordination for each HLS performance setting.

\section{Conclusion}

This paper presents the investigation of the controllability of an aircraft with a segmented active high-lift system along the wingspan. Each flap has a separate compressor which can be individually controlled. Symmetric increase or asymmetric increase in compressor performance on the wing results in a climbing or rolling motion. Using the method of asymmetric blowing handling quality criteria for roll motion can be fulfilled. Furthermore, the direct lift force caused by symmetric blowing can generate considerable climb rates of the aircraft.

Another part of the research was the simulation of the maneuver flight capability with high-lift control inputs. The results show that a simultaneous change in altitude and heading is possible. The dynamic behavior of the compressor has a considerable influence on the maneuver capability. If the eigen frequency of the compressor is too low, a maneuver flight is not possible.

Due to the fact that each high-lift system segment has a considerable influence on the local aerodynamic of the wing, a failure of a single segment causes considerable aircraft reactions. In this investigation, the resulting rolling motion and lift loss due to single blowing system failure are counteracted using the remaining segments settings on the affected wing. The developed control strategy shows acceptable results. However, the ability to fly a climb and bank maneuver simultaneously with a compressor failure is critical. The simulation results show that the performance limits of the system are reached quickly. For further investigation, the remaining segments on the opposite wing have to be taken into account for failure compensation to avoid such limitations.

Next steps will be the extension of the model by drag and thus yawing influences. In cooperation with the partner projects in compressor research, a remedy has to be found between the necessary compressor dynamics for control and the realizable performance of such small scale units. The performance of the control system will be increased further, by optimized gains, control strategy adaptation, as well as by more detailed modeling of the underlying aerodynamic effects.

Acknowledgements This work has been supported by CFD results from DLR's Tau code generated by Dennis Keller [Institute of Aerodynamics and Flow Technology (AS), DLR (German Aerospace Center)]. The reference aircraft design has been developed by Wolfgang Heinze [Institute of Aircraft Design and Lightweight Structures (IFL), TU Braunschweig] with the preliminary aircraft design tool PrADO. 


\section{References}

1. Lachmann, G.V. (ed.): Boundary Layer and Flow Control. Pergamon Press, Oxford (1961)

2. Englar, R.J., Circulation control pneumatic aerodynamics: Blown force and moment augmentation and modification; past, present \& future. In: Fluids 2000 Confercence and Exhibit, AIAA 2000-2541 (2000). https://doi.org/10.2514/6.2000-2541

3. Werner-Spatz, C., Heinze, W., Horst, P., Radespiel, R.: Multidisciplinary conceptual design for aircraft with circulation control high-lift systems. CEAS Aeronaut. J. 3(2), 145-164 (2012). https://doi.org/10.1007/s13272-012-0049-5

4. Werner-Westphal, C., Heinze, W., Horst, P.: Multidisciplinary integrated preliminary design applied to future green aircraft configurations. In: 45th AIAA Aerospace Sciences Meeting and Exhibit (American Institute of Aeronautics and Astronautics, 2007). https://doi.org/10.2514/6.2007-655

5. Coandă, H.: Device for deflecting a stream of elastic fluid projected into an elastic fluid. US Patent 2,052,869 (1936)

6. Quigley, H.C., Innis, R.C.: Handling qualities and operational problems of a large four-propeller STOL airplane. Technical Note D-1647, NASA (1963)

7. Quigley, H.C., Lawson, H.F.: Simulator study of the lateral-directional handling qualities of a large four-propellered STOL transport airplane. Technical Note D-1773, NASA (1963)

8. Quigley, H.C., Innis, R.C., Vomaske, R.F., Ratcliff, J.W.: A flight and simulator study of directional augmentation criteria for a four-propellered STOL airplane. Technical Note D-3909, NASA (1967)

9. Holzhauser, C.A., Innis, R.C., Vomaske, R.F.: A flight and simulator study of the handling qualities of a deflected slipstream STOL seaplane having four propellers and boundary-layer control. Technical Note D-2966, NASA (1965)

10. Dansby, T., Garrard, W.C.J., Ryle, D.M., Sullivan, L.J.: V/STOL development of the C-130 Hercules. AIAA J. Aircr. 1(5), 242-252 (1964)

11. Holzhauser, C.A., Deckert, W.H., Quigley, H.C., Kelly, M.W.: Design and operating considerations of commercial STOL transports. AIAA J. Aircr. 2(2), 87-93 (1965)

12. May, F., Widdison, C.: STOL High-Lift Design Study Volume 1. State-of-the-Art Review of STOL Aerodynamic Technology.
Institutsbericht AFFDL-TR-71-26-Vol. 1, The Boeing Company, Air Force Flight Dynamics Laboratory, Air Force Systems Command, Wright-Patterson Air Force Base, Ohio (1971)

13. Cook, M.V., Buannanno, A., Erbslöh, S.D.: A circulation control actuator for flapless flight control. RAS Aeronaut. J. 112(1134), 483-89 (2008)

14. Burnazzi, M., Radespiel, R.: Synergies between suction and blowing for active high-lift flaps. CEAS Aeronaut. J. 6(2), 305-318 (2015). https://doi.org/10.1007/s13272-014-0146-8

15. Keller, D., Rudnik, R.: Numerical investigation of engine effects on a transport aircraft with circulation control. J. Aircr. 52(2), 421-438 (2015). https://doi.org/10.2514/1.C032724

16. Diekmann, J.H.: Analysis of trimmable conditions for a civil aircraft with active high-lift system. CEAS Aeronaut. J. 6(1), 109-120 (2015). https://doi.org/10.1007/s13272-014-0132-1

17. Diekmann, J.H., Hahn, K.U.: Effect of an active high-lift system failure during landing approaches. CEAS Aeronaut. J. 6(2), 181-196 (2015)

18. Diekmann, J.H.: Flight mechanical challenges of STOL aircraft using active high-lift. In: AVIATION AIAA Applied Aerodynamics Conference, AIAA-2017-3561. American Institute of Aeronautics and Astronautics, Denver (2017)

19. Diekmann, J.H., Keller, D., Faez, E., Rudnik, R., Gollnick, V.: Flight mechanics model for spanwise lift and rolling moment distributions of a segmented active high-lift wing. CEAS Aeronaut. J. 8(4), 625-635 (2017). https://doi.org/10.1007/s13272017-0261-4

20. Pichler, M.: Steuerbarkeit eines Flugzeugs mit aktivem Hochauftriebssystem mithilfe eines entlang der Spannweite segmentweise kontrollierbaren Klappensystems. Internal Report DLR-IB-FT-BS-2017-21, Institut für Flugsystemtechnik, DLR \& Institut für Flugführung, TU Braunschweig. Masterthesis (2017)

21. MIL-HDBK-1797A.: Flying qualities of piloted aircraft. Military Handbook, Department of Defense (1997)

22. Brockhaus, R., Alles, W., Luckner, R.: Flugregelung. Springer, Berlin (2010)

23. Teichel, S., Verstraete, T., Seume, J.: Optimised multidisciplinary design of a small transonic compressor for active high-lift systems. In: International Gas Turbine Congress. GTSJ, Tokyo (2015) 